\title{
Preface
}

\section{Action on injury: setting the agenda for children and young people in the UK}

\author{
Barry Pless
}

This is truly an historic occasion. This supplement and the conference which launches it could, and should, prove pivotal in the history of injury prevention in the UK. Some may think it naive to assume that any conference, let alone any single document, can change the course of history. But events have proven otherwise. There are many examples in the world of politics, and even in science, but the closest parallel in the case of injury is the publication of Injury in America. ${ }^{1}$ As Professor Susan Baker explains in the Foreword, that conference and the document that followed had a profound effect on events in the United States. These culminated in the establishment of the National Centre for Injury Prevention and Control. By so doing, the United States joined the "big league" of players on the injury control scene: countries like Sweden, Australia, and New Zealand. In my view, this supplement and conference will most assuredly reach its objective if something similar happens in the UK. If not, this country may continue to languish in the backwaters.

It may well be that conferences such as this only serve to ratify decisions that policy makers have already made or are inclined to make. Whether this is the case, or whether it works the other way around, matter little. The important issue is that there be a sensible and appropriate response to the issues raised. By appropriate, I mean one that is commensurate with the size and seriousness of the problem injuries represent. Equally important is that the response be made quickly. With each day of delay, lives are lost that could be saved; children are disfigured or disabled who could remain healthy. Thus, major steps must be taken in the UK, or any country for that matter, if it is genuinely serious about preventing these and other disturbing consequences of childhood injuries. Minor steps are certain to be insufficient. In the papers presented in this supplement powerful evidence is provided in support of the desperate need for action.

The contributors remind us first of the enormous toll injuries bring. Equally important, they remind us of the extent to which most are preventable and of the measures adopted. They call attention to the need to implement what has already been proven to be effective. My task, basically, is to reinforce these messages. As an outsider it is perhaps presumptuous to use this forum to press for a solid and immedi- ate response, especially from those in government, but I feel a powerful obligation to do so. Anything less would be a betrayal of my responsibility as editor, scientist, colleague, and parent.

Accordingly, I begin by underscoring the great paradox injury prevention presents as a public health problem. This is a field par excellence in which so much is known and so little implemented. It is a field that is every bit as much a health problem as heart disease or cancer, but which receives scant attention from most physicians and even from many public health officers. Injury prevention gets far less funding for research than many diseases that affect far fewer people. There is virtually no government funding for the many voluntary groups that do yeoman work in trying to stem the tide of death and disability from injuries.

\section{Magnitude}

Injuries represent a burden on the health system that is far greater than that arising from many more popular diseases. Most countries in the developed world spend large amounts of their health budget on diseases for which a vocal constituency exists or those that are regarded by physicians as interesting or important. Unlike most popular diseases, however, injuries are much more readily, easily, and inexpensively preventable.

\section{DISPROPORTIONATE RESPONSES}

Worldwide, large chunks of funding for research and for care are invested in surprisingly few diseases. Some archaic diseases remain prominent foci of public health activity, whereas injuries continue to be ignored in most countries. Fortunately, in the UK, all this has begun to change. The appointment of a minister of public health is a major step in the right direction. Similarly, the importance placed by the transport minister in matters related to safety is a welcome breath of fresh air. Yet, in concrete terms, especially funding, the inequities persist. Why is this?

The most likely explanation for the seemingly irrational allocation of resources between other diseases and injuries is that policy makers, like much of the public, continue to view injuries as "accidents", that is, random acts of bad luck, and accordingly, not amenable 
to prevention. Another possible reason is that, as has been suggested, there are no national bodies of injury victims or their families pressing for more help. Nevertheless, unless and until policy makers are fully convinced that injuries are a preventable disease, we cannot expect more resources to be allocated to them. Those who control the purse strings must be persuaded that most injuries are truly preventable and that the cost of failing to do so greatly outweighs the relatively small costs of prevention. In several places in this supplement figures are given that convincingly make this point.

PREVENTION: PREACHED MUCH AND PRACTISED LITTLE

It is curious that in spite of a culture that allegedly prefers prevention to cure, most countries fail to invest sufficient resources to make this preference a reality. Even more curious is how often, when such expenditures are made, they are directed at conditions for which the means of prevention are not clear or not well supported by scientific evidence. Yet, when it comes to injury prevention, the situation is the reverse: in spite of solid proof that prevention is effective, little is spent.

What must be done in the UK and elsewhere to change this? Three steps must be taken.

\section{Funding}

It is inescapable that sufficient funds must be allocated to injury prevention, both for research and for the implementation of programmes now known to be effective or those that will be shown to be so in the future. Surprisingly, perhaps, the amounts of money involved need not be great. Many of the most effective solutions rest on legislation or regulation. It costs little to introduce such measures, yet there is much evidence that, for example, laws regarding the use of helmets succeed in preventing head injuries. Similarly, laws to lower speed limits are cheap and effective and although speed cameras are more costly, these costs pale by comparison with those involved in caring for a seriously injured crash victim. Caring for a child or adult with a serious head injury-one that requires constant life support or life long rehabilitation-costs the state several million pounds yearly. There are, of course, significant costs related to enforcement of any legislation. But evidence suggests that even without enforcement, the desired objective is achieved in part once such legislation has been introduced and widely publicised.

Needless to say, not all injuries can be prevented simply by passing or enforcing laws. Many will require extensive mass education, health promotion, and variants of old fashioned health visiting. Others will require imaginative approaches that may be best implemented by voluntary bodies. But if these groups are expected to become more heavily involved in doing what is in some respects the job of public health, it is only reasonable to provide them with adequate support for doing so. These groups require not only financing for specific projects, but continuing funding for administrative costs, including key staff. Forcing them to live hand-to-mouth, with work reflecting sponsor's preferences rather than the reverse, is unacceptable. It is not reasonable for government to have it both ways - to save money and still expect the work to be done.

Finally, funding for research is inadequate. In spite of the surprisingly large knowledge base in injury prevention, there are massive gaps and many unanswered questions. These range from acquiring a better understanding of the role of sex differences in injury occurrence to the development of better methods to measure exposure to risk. Above all, evaluation research is needed whenever a new programme is introduced.

\section{Establishing jurisdiction}

The notion of "jurisdiction" may appear strange in the context of a discussion of a health issue. Perhaps "responsibility" is a better term, but there are some nuances conveyed by the former that seem important. As two tables in a later section make clear, in spite of widespread underfunding, the list of injury prevention players, governmental, private, and voluntary, is large. The difficulty is that when so many are involved there is a great likelihood that there will be considerable duplication of efforts and, more worrisome, important areas that are overlooked.

The present situation in the UK is such that there is no single agency, branch, or department with the jurisdictional mandate or responsibility to coordinate the work of all the others involved and no body to ensure that there are no major omissions. To be sure, this is a complex and sensitive issue, but establishing jurisdiction-deciding who has the ultimate responsibility and power, if necessary, to override decisions or policies of other players-is, in my view, essential.

What makes this so difficult are the political considerations involved. As has been stated, in the UK as in most countries, different branches of government as well as many in the voluntary and private sector each play a part. It is a delicate matter for one department to say to another, "on this particular issue your decisions have not taken the safety of our children fully into account; consequently, we intend to have those decisions reversed".

In an ideal world, all the actors would work smoothly together to achieve a common goal. They would share a value system that places health and safety well above protecting the profits of merchants or manufacturers or the need to move traffic quickly. Regrettably, in the real world, this is not the way life unfolds. Therefore, without clear and strong leadership, the UK cannot hope to achieve what was long ago accomplished in Sweden and what is rapidly emerging in the United States, Australia, and New Zealand.

To my way of thinking, that should come from the health sector. Because treating those with injuries is the responsibility of the medical 
care system, so too should the main responsibility for their prevention fall to health departments. Whether that responsibility lies more squarely in the public health arena than that of clinical medicine is a secondary issue. Probably some mixture of both is what is needed.

Both clinical medicine and public health can contribute in important ways. The evidence is not convincing that clinicians providing counselling are effective in changing behaviour or lifestyle, but it is likely that better studies, viewing counselling or education as a complement to other strategies, would demonstrate that physicians or nurses are an important ingredient in the recipe for success.

Similarly, the evidence for public health manoeuvres, such as home visits that include injury prevention counselling or home safety checks, for example, is also somewhat inconclusive. Although in the studies reviewed by Roberts et al, not all home visits were conducted by public health nurses, the rationale for their doing so is compelling. ${ }^{2}$ These nurses are the foot soldiers of public health and for interventions that require personal, one-onone contacts, there is no reasonable substitute.

Despite these distinctive contributions from health, as matters now stand many other branches of government, central and local, have a greater stake in injury prevention that does any part of the health sector. Consider the example of road safety: it is Transport that decides on most aspects of road design and it is Justice that decides on penalties for drunkdriving, speeding and other such violations. With respect to other safety issues, it is Trade and Industry that regulates unsafe or potentially dangerous products and Housing that establishes codes or regulation intended to prevent injuries to young children and the elderly. The list is a lengthy one, but rarely does it include health.

Moreover, there are many other parties who are neither parts of government nor parts of the health system whose skills and commitment also need to be mobilised to enhance safety. Both the engineering and technology sectors have made enormous contributions through the invention of devices like helmets, seat restraints, and airbags. They must be encouraged to do so by being repeatedly reminded that safety is an important component of profit in most enterprises.

Is it unrealistic to suggest that health departments assume greater responsibilities for this problem? Obviously in light of this supplement it is not. The question that remains, however, is precisely how far should health departments travel along this route and by what means? The contributors to this supplement have gone a long way towards providing answers to that question. In the discussion based on these thoughtful papers, no doubt there will be other ideas expressed to complete the agenda. I expect that many efforts will be made to remind us that a major part of the problem is being tackled by the voluntary sector, for example, by groups like the Child Accident Prevention Trust and the Royal Society for the Prevention of Accidents and, on occasion, by the private sector. Such a reminder should not be needed.

\section{National centres for injury prevention}

Several key elements form the bottom line for those reading this supplement who are determined that "action" be taken. Apart from actions needed to provide a stronger sense of direction and serious discussions about responsibility, leadership, and coordination, there must emerge clear evidence of commitment. When infant mortality rates in many countries lagged behind those of Japan, to match those enviable numbers, most countries, including the UK, succeeded because a commitment was made to do so. For a long while Swedish injury fatality rates have represented an analogous target; they tell us what is possible. With determination, organisation, and an appropriate allocation of resources such rates should easily be achievable in the UK.

In the end, government and others must agree that the prevention of injuries is an urgent priority. This will not be an easy task and doubtless it will require strong leadership from someone or some group. Sweden's success was largely attributable to inspired leadership from a pioneering figure; America's achievements are attributed to a timely document from a prestigious source. In both cases, the mechanism established to ensure the success of the commitment was the equivalent of a national centre for injury prevention. The UK cannot hope to succeed without something similar.

It is of interest that the government is committed to reducing inequities in health status. I applaud this because there are few areas in health in which the disparities between rich and poor are more noteworthy and more deplorable than in the case of children's injuries of almost every kind. If only to achieve this laudable goal, national centres must be established in England, Northern Ireland, Scotland, and Wales to ensure that the needed Action on Injury is taken fully and promptly.

1 Committee on Trauma Research, Commission on Life Sciences, National Research Council and Institute of Medicine. Injury in America: a continuing public health problem. Washington, DC: National Academic Press, 1985.

2 Roberts I, Kramer MS, Suissa S. Does home visiting prevent childhood injury? A systematic review of randomised controlled trials. BMF 1996;312:29-33. 